\title{
Produção de capim elefante e movimentação de cátions em função de gesso mineral
}

\author{
Renato L. dos Santos ${ }^{1}$, Fernando J. Freire ${ }^{2}$, Vinícius M. de Azevedo², \\ Alexandre T. da Rocha ${ }^{3} \&$ José A. Tavares ${ }^{4}$
}

\begin{abstract}
RESUMO
O uso de gesso na correção da acidez trocável em subsuperfície tem proporcionado melhoria do ambiente radicular, influenciando positivamente na produtividade das culturas. Portanto, o objetivo foi avaliar o potencial do gesso de origem mineral da região do Araripe, em Pernambuco, na elevação dos teores de Ca trocável e na redução dos teores de Al trocável em subsuperfície e no aumento da produção de biomassa de variedades de capim elefante. Para isto foram cultivadas em campo três variedades de capim elefante: Cameroon, Gramafante e Roxo, na presença e na ausência de gesso mineral em arranjo fatorial $(3 \times 2)$ com os tratamentos distribuídos casualmente em 4 blocos. Os teores de $\mathrm{Ca}^{2+}, \mathrm{S}_{-} \mathrm{SO}_{4}{ }^{2-}, \mathrm{Al}^{3+}$ e sua saturação não foram influenciados pela aplicação de gesso mineral na camada subsuperficial. A aplicação de gesso mineral reduziu o $\mathrm{pH}$ do solo na camada subsuperficial. O cultivo da variedade de capim Cameroon promoveu aumento do $\mathrm{pH}$ do solo, redução do teor e da saturação por Al. Os capins elefantes Cameroon e Gramafante apresentaram elevadas produções de matéria seca porém apenas a variedade Cameroon apresentou resposta à aplicação de gesso mineral, que alcançou $33 \mathrm{Mg} \mathrm{ha}^{-1}$.
\end{abstract}

Palavras-chave: movimentação de cátions, acidez subsuperficial, gipsita, Pennisetum purpureum Schum

\section{Yield of elephant grass and movement of cations as a function of mined gypsum}

\begin{abstract}
The use of gypsum in context of exchangeable acidity in subsurface has provided the improvement of root environment, positive influence on crop yields. Therefore, the aim of this study was to evaluate the potential of the mined gypsum from the Araripe region in increasing the exchangeable $\mathrm{Ca}$ and also the reduction of exchangeable $\mathrm{Al}$ in subsurface, and increase in biomass production of varieties of elephant grass. The experiment was composed of three varieties of elephant grass, such as, Cameroon, Gramafante and Roxo in the presence and absence of mined gypsum through a factorial arrangement $(3 \times 2)$, with treatments arranged in 4 randomized blocks. The levels of $\mathrm{Ca}^{2+}, \mathrm{S}_{-} \mathrm{SO}_{4}{ }^{2-}, \mathrm{Al}^{3+}$ and also its saturation were not affected by the application of mined gypsum in the soil subsurface layer. The application of mined gypsum reduced the $\mathrm{pH}$ of the soil subsurface layer. The growing of Cameroon variety promoted the increase in soil pH, reducing the $\mathrm{Al}$ saturation. The Cameroon and Gramafante had high dry matter yields, but only the Cameroon variety presented response to application of gypsum, which reached $33 \mathrm{Mg} \mathrm{ha}^{-1}$.
\end{abstract}

Key words: movement of cations, acidity subsurface, gypsite, Pennisetum purpureum Schum

${ }^{1}$ IFPE, Campus Vitória de Santo Antão, Propriedade Terra Preta, s/n, Zona Rural, CEP 55600-000, Vitória de Santo Antão, PE. Fone: (81) $3523-1130$. E-mail: renato.santos@vitoria.ifpe.edu.br

${ }^{2}$ UFRPE, Sede, Rua Dom Manoel de Medeiros, s/n, Dois Irmãos, CEP 52171-900, Recife, PE. Fone: (81) 3320-6220. E-mail: f.freire@depa.ufrpe.br; vinicius_179@hotmail.com

${ }^{3}$ UFRPE, Unidade Acadêmica de Serra Talhada, Fazenda Saco, s/n, C. P. 63, CEP 56909-460, Serra Talhada, PE. Fone: (87) 3929-3003. E-mail: alexandre@uast.ufrpe.br

${ }^{4}$ IPA, Rodovia Araripina - PE 585, km 18, CEP 56280-000, Araripina, PE. Fone: (87) 9161-0916. E-mail: j.alvestavares@gmail.com 


\section{INTRODUÇÃO}

A matéria seca produzida pelo capim elefante (Pennisetum purpureum Schum) pode ser utilizada como biomassa alternativa na produção energética no Sertão do Araripe, PE (Morais et al., 2009; Santos et al., 2012). Para isto são necessárias pesquisas relacionadas às suas exigências químicas de solo, principalmente em virtude da região apresentar solos ácidos que exigem correção em superfície e em subsuperfície (Millán et al., 2010).

Os solos da Chapada do Araripe, Pernambuco, são Latossolos que se apresentam ácidos, profundos, sem incremento significativo de argila entre os horizontes e baixa fertilidade natural (Cavalcanti \& Lopes, 1994). Associados a essas características podem ser encontrados, ainda, teores tóxicos de $\mathrm{Al}^{3+}$ em subsuperfície o que restringe o crescimento do sistema radicular das plantas e, em consequência, o acesso da água e nutrientes, além de inibir a absorção e translocação de P para a parte aérea das plantas (Rheinheimer et al., 1994; Abichequer et al., 2003).

A prática mais eficiente na correção da acidez é a calagem porém, devido à baixa solubilidade e à mobilidade do calcário, não é possível alcançar resultados satisfatórios em subsuperfície visto que sua atuação fica restrita ao local de aplicação (Ernani et al., 2001). Neste sentido, vários autores têm estudado o uso do gesso como corretivo da acidez trocável em subsuperfície material este de origem industrial (Caíres et al., 2006; Soratto \& Crusciol, 2008) ou mineral (Saldanha et al., 2007; Rocha et al., 2008). O gesso de origem industrial é um resíduo da produção de ácido fosfórico e o gesso mineral é oriundo, em especial, da gipsita $\left(\mathrm{CaSO}_{4} 2 \mathrm{H}_{2} \mathrm{O}\right)$ mas também de outros minerais como a anidrita $\left(\mathrm{CaSO}_{4}\right)$. Em Pernambuco, sobretudo no Pólo Gesseiro do Araripe, esses minerais se apresentam em grandes reservas de origem sedimentar associadas a depósitos evaporíticos (Saldanha et al., 2007).

Neste contexto, o uso do gesso de origem mineral produzido na própria região do Araripe pode potencializar a produção de matéria seca do capim elefante por sua atuação na correção da acidez trocável em subsuperfície proporcionando maior quantidade de biomassa, a qual pode ser utilizada como fonte de energia alternativa na calcinação da gipsita da indústria gesseira do Araripe. Esta calcinação é dependente da queima de lenha da caatinga que se tem tornado escassa, além de comprometer ecologicamente este bioma de larga importância para o Nordeste do Brasil. A correção por meio do uso de gesso mineral se relaciona com a movimentação de Ca para camadas mais profundas do solo e, consequentemente, redução da acidez trocável e do efeito tóxico do excesso de Al proporcionando um número maior de raízes em profundidade (Rocha et al., 2008).

$\mathrm{O}$ objetivo foi avaliar o potencial do gesso de origem mineral do Araripe na elevação do teor de Ca trocável e na redução do teor de $\mathrm{Al}$ trocável em subsuperfície e sua influência na produção de biomassa de diferentes variedades de capim elefante na Chapada do Araripe, em Pernambuco.

\section{Material e Métodos}

Conduziu-se, no período de janeiro a setembro de 2010, um experimento a campo na Estação Experimental de Araripina do
Instituto Agronômico de Pernambuco (IPA), nas coordenadas geográficas $07^{\circ} 27^{\prime} \mathrm{S}$ e $40^{\circ} 24^{\prime} \mathrm{W}$ e altitude de $831 \mathrm{~m}$, em um solo classificado como Latossolo Amarelo (Cavalcanti \& Lopes, 1994). A vegetação local é composta, basicamente, por Caatinga Hiperxerófila com trechos de Floresta Caducifólia. O clima é do tipo Tropical Semiárido, com chuvas de verão, tendo o período chuvoso com início em novembro e término em abril (CPRM, 2005) e a precipitação no período foi de 350,2 mm (Figura 1).

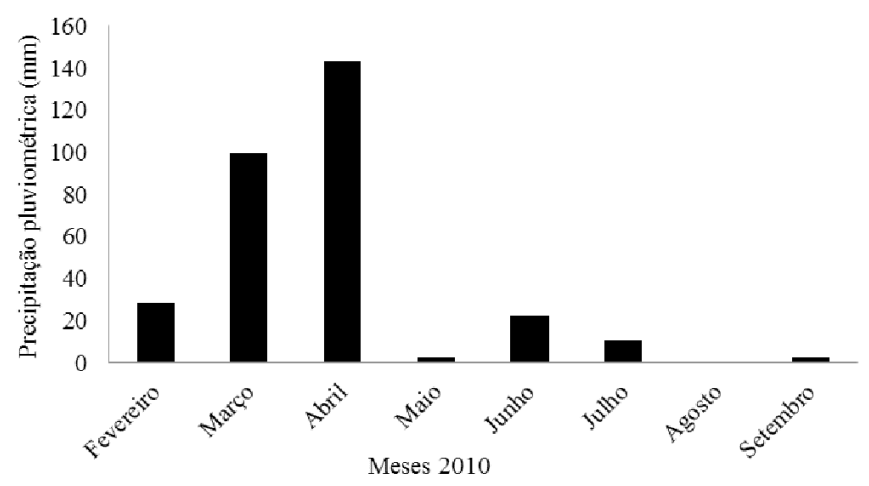

Figura 1. Pluviometria durante o ensaio experimental na Estação Experimental do Instituto Agronômico de Pernambuco

Os atributos químicos e físicos do solo (Tabela 1 ) foram determinados em duas profundidades $(0,0$ a $0,2 \mathrm{~m}$ e 0,2 a 0,4 $\mathrm{m})$, nas quais se determinaram $\mathrm{pH}\left(\mathrm{H}_{2} \mathrm{O}\right), \mathrm{pH}\left(\mathrm{CaCl}_{2} 0,01\right.$ mol L $\left.{ }^{-1}\right), \mathrm{Ca}^{2+}, \mathrm{Mg}^{2+}, \mathrm{K}^{+}, \mathrm{Na}^{+}, \mathrm{Al}^{3+},(\mathrm{H}+\mathrm{Al}), \mathrm{P}, \mathrm{COT}$ (carbono orgânico total), $\mathrm{S}^{-} \mathrm{SO}_{4}{ }^{2-}$, capacidade máxima de adsorção de sulfato (CMAS) e P-remanescente (P-rem). Exceto o S-SO ${ }_{4}^{2-}$ disponível, a CMAS e o P-rem que foram determinados segundo Alvarez V. et al. (2001); as demais análises seguiram as metodologias descritas pela EMBRAPA (2009). Fisicamente, o solo foi caracterizado quanto à sua granulometria para definição de sua classe textural; densidade do solo; densidade de partículas; condutividade hidráulica e, indiretamente, a porosidade total. Com exceção da granulometria, determinada pelo método da pipeta adaptado por Ruiz (2005) as demais análises físicas foram realizadas de acordo com as metodologias propostas pela EMBRAPA (1997).

Foram utilizadas três variedades de capim elefante (Roxo, Cameroon e Gramafante), submetidas a duas doses de gesso, 0 e $494 \mathrm{~kg} \mathrm{ha}^{-1}$ (Alvarez V. et al., 1999), aplicadas no fundo do sulco de plantio a $0,3 \mathrm{~m}$ de profundidade. $\mathrm{O}$ ensaio foi disposto em delineamento de blocos casualisados e os tratamentos arranjados em esquema fatorial ( $3 \times 2$ ), como parcela subdividida, com quatro repetições. A subparcela foi composta por 7 sulcos de $6 \mathrm{~m}$ de comprimento e espaçados $1 \mathrm{~m}$, perfazendo a área total de $42 \mathrm{~m}^{2}$. A área útil foi formada pelas três linhas centrais descartando-se $1 \mathrm{~m}$ das extremidades, totalizando $12 \mathrm{~m}^{2}$.

$\mathrm{O}$ experimento foi instalado no início das chuvas (Figura 1) sendo precedido da aplicação e incorporação, até $0,2 \mathrm{~m}$ de profundidade de calcário dolomítico a lanço em área total, em que a Necessidade de Calagem (NC) correspondeu a 0,550 $\mathrm{Mg} \mathrm{ha}^{-1}$ (IPA, 2008) e pela aplicação do gesso mineral. Oito dias após a aplicação dos corretivos foi realizou-se o plantio das variedades de capim elefante utilizando-se cerca de 4,0 $\mathrm{Mg} \mathrm{ha}^{-1}$ de colmo com três meses de idade, dispostos em duas 
Tabela 1. Atributos químicos e físicos do solo nas profundidades de 0-0,20 m e 0,20 - 0,40 m na área do ensaio de campo na Estação Experimental de Araripina do Instituto Agronômico de Pernambuco

\begin{tabular}{|c|c|c|}
\hline \multirow{2}{*}{ Atributo } & \multicolumn{2}{|c|}{ Profundidade (m) } \\
\hline & $0-0,20$ & $0,20-0,40$ \\
\hline $\mathrm{pH}_{\text {áqua }}(1: 2,5)$ & 4,85 & 4,54 \\
\hline $\mathrm{pH} \mathrm{CaCl} 2(1: 2,5)$ & 3,30 & 3,40 \\
\hline $\mathrm{Ca}^{2+}\left(\mathrm{cmol}_{\mathrm{c}} \mathrm{dm}^{-3}\right)$ & 0,95 & 0,30 \\
\hline $\mathrm{Mg}^{2+}\left(\mathrm{cmol}_{\mathrm{c}} \mathrm{dm}^{-3}\right)$ & 0,68 & 0,38 \\
\hline $\mathrm{K}^{+}\left(\mathrm{cmol}_{\mathrm{c}} \mathrm{dm}^{-3}\right)$ & 0,14 & 0,09 \\
\hline $\mathrm{Na}^{+}\left(\mathrm{cmol}_{\mathrm{C}} \mathrm{dm}^{-3}\right)$ & 0,23 & 0,24 \\
\hline$P\left(m g d^{-3}\right)$ & 4,00 & 1,00 \\
\hline P-rem $\left(\mathrm{mg} \mathrm{L}^{-1}\right)^{1}$ & 62,95 & 58,28 \\
\hline $\mathrm{Al}^{3+}\left(\mathrm{cmol}_{\mathrm{C}} \mathrm{dm}^{-3}\right)$ & 0,37 & 0,70 \\
\hline$(\mathrm{H}+\mathrm{Al})\left(\mathrm{cmol}_{\mathrm{c}} \mathrm{dm}^{-3}\right)$ & 3,74 & 3,27 \\
\hline COT $\left(g^{k g}{ }^{-1}\right)^{2}$ & 8,1 & 5,2 \\
\hline $\mathrm{S}-\mathrm{SO}_{4}^{-2}\left(\mathrm{mg} \mathrm{dm}{ }^{-3}\right)$ & 1,83 & 0,69 \\
\hline CMAS $\left(\mathrm{mg} \mathrm{g}^{-1}\right)^{3}$ & 0,012 & 0,018 \\
\hline $\mathrm{CTC}_{\text {eftetiva }}\left(\mathrm{cmol}_{\mathrm{c}} \mathrm{dm}^{-3}\right)^{4}$ & 2,37 & 1,71 \\
\hline $\mathrm{m}(\%)^{5}$ & 15,49 & 40,90 \\
\hline$V(\%)^{6}$ & 84,39 & 59,06 \\
\hline PST $(\%)^{7}$ & 3,95 & 5,49 \\
\hline Areia Total $\left(\mathrm{g} \mathrm{kg}^{-1}\right)$ & 729,75 & 722,28 \\
\hline Areia Grossa $\left(\mathrm{g} \mathrm{kg}^{-1}\right)$ & 569,81 & 551,49 \\
\hline Areia Fina $\left(\mathrm{g} \mathrm{kg}^{-1}\right)$ & 159,94 & 170,79 \\
\hline Silte $\left(\mathrm{g} \mathrm{kg}^{-1}\right)$ & 133,88 & 143,75 \\
\hline Argila $\left(\mathrm{g} \mathrm{kg}^{-1}\right)$ & 136,38 & 133,97 \\
\hline Classe Textural & Franco-arenosa & Franco-arenosa \\
\hline $\mathrm{Dp}\left(\mathrm{kg} \mathrm{dm}^{-3}\right)^{8}$ & 2,99 & 2,98 \\
\hline Ds $\left(\mathrm{kg} \mathrm{dm}^{-3}\right)^{9}$ & 1,43 & 1,41 \\
\hline PТ (\%) 10 & 52,26 & 52,64 \\
\hline $\mathrm{K}_{0}\left(\mathrm{~mm} \mathrm{~h}^{-1}\right)^{11}$ & 65,24 & 92,83 \\
\hline
\end{tabular}

'Fósforo remanescente; ${ }^{2}$ Carbono orgânico total; ${ }^{3}$ Capacidade máxima de adsorção de sulfato; ${ }^{4}$ Capacidade de troca de cátions; ${ }^{5}$ Saturação por alumínio; ${ }^{6}$ Saturação por bases; ${ }^{7}$ Porcentagem de sódio trocável; ${ }^{8}$ Densidade da partícula; ${ }^{9}$ Densidade do solo; ${ }^{10}$ Porosidade total; ${ }^{11}$ Condutividade hidráulica saturada

fileiras sendo, em seguida, rebolados em toletes com 4 a 5 gemas, pulverizados com cupinicida e posteriormente realizado o fechamento do sulco.

Todas as parcelas receberam $300 \mathrm{~kg} \mathrm{ha}^{-1}$ de sulfato de amônio (20\% de N), $286 \mathrm{~kg} \mathrm{ha}^{-1}$ de superfosfato triplo ( $40 \%$ de $\left.\mathrm{P}_{2} \mathrm{O}_{5}\right)$ e $150 \mathrm{~kg} \mathrm{ha}^{-1}$ de cloreto de potássio $\left(60 \%\right.$ de $\left.\mathrm{K}_{2} \mathrm{O}\right)$ calculados de conformidade com as Recomendações de Adubação para o Estado de Pernambuco (IPA, 2008).

Aos 221 dias após a aplicação do gesso mineral amostras de solo foram coletadas na área útil das parcelas experimentais nas profundidades 0,0-0,2 m e 0,2-0,4 m, com o auxílio de enxadeco e pá reta. As perfurações para obtenção das amostras foram feitas a aproximadamente $0,25 \mathrm{~m}$ de distância da linha de plantio do capim elefante, sendo coletadas 5 amostras simples por subparcela para a formação de uma composta, disposta em duas diagonais cruzadas na área útil; posteriormente, as amostras de solo coletadas foram secadas ao ar, destorroadas e tamisadas em peneira de malha de $2 \mathrm{~mm}$; em seguida, procedeu-se à determinação do $\mathrm{pH}\left(\mathrm{H}_{2} \mathrm{O}\right), \mathrm{Ca}^{2+}, \mathrm{Mg}^{2+}, \mathrm{K}^{+}, \mathrm{Al}^{3+}$, e S-SO ${ }_{4}^{2-}$. Os métodos utilizados foram os mesmos descritos anteriormente na caracterização química da área experimental. Foram calculadas as relações $\mathrm{Ca} / \mathrm{Mg}$ e $\mathrm{Ca} / \mathrm{K}$ e a saturação por $\mathrm{Al}$.

O corte e a avaliação das variedades de capim elefante foram realizados aos 213 dias após o plantio. Foram coletadas 10 plantas aleatoriamente na parcela útil, sendo posteriormente pesadas e trituradas em forrageira. As subamostras de biomassa foram secadas em estufa de circulação forçada de ar a 65 ${ }^{\circ} \mathrm{C}$, até atingir peso constante e posteriormente trituradas e acondicionadas em sacos plásticos. Com base no número de perfilhos por metro linear foi possível estimar a produção da parcela útil corrigindo-se as falhas da brotação do material utilizado no plantio.

Os dados das variáveis foram submetidos à análise da variância (ANOVA) e testados pelo teste $\mathrm{F}(\mathrm{p} \leq 0,05)$. Nas variáveis cujos efeitos principais e/ou interação foram significativos, aplicou-se o teste de comparação de médias de Tukey $(\mathrm{p} \leq 0,05)$.

\section{Resultados e Discussão}

Os teores de Ca no solo nas camadas superficial e subsuperficial não foram influenciados pelos tratamentos (Tabela 2). É provável que o $\mathrm{Ca}$ adicionado ao solo pelo gesso mineral, tenha sido lixiviado para camadas inferiores às estudadas pela solubilização do material, facilitada pelos elevados índices pluviométricos que ocorreram logo após a aplicação do gesso mineral (Figura 1) aliados aos altos teores de areia nas profundidades 0 a $0,2 \mathrm{~m} \mathrm{e}$ 0,2 a $0,4 \mathrm{~m}$, respectivamente, representados por 729,75 e 722,28 $\mathrm{g} \mathrm{kg}^{-1}$ (Tabela 1), o que diminui a capacidade do solo em reter o Ca (Alvarez V. et al., 1999).

Outros pesquisadores têm observado, trabalhando com gesso, aumento no teor de $\mathrm{Ca}$ em subsuperfície, porém em condições edafoclimáticas diferentes às deste trabalho, em especial o teor de argila. Segundo Ernani et al. (2001) em ensaio conduzido em casa de vegetação em amostras de Latossolo e Cambissolo com, respectivamente, 550 e $410 \mathrm{~g} \mathrm{~kg}^{-1}$ de argila, o gesso percolou Ca no perfil do solo, sobremaneira quando incorporado aos solos. Essas amostras ficaram incubadas 30 dias com umidade de aproximadamente $80 \%$ do teor de água retido na capacidade de campo e, posteriormente, em colunas de lixiviação receberam $300 \mathrm{~mm}$ de água. De acordo com Rocha et al. (2008) o intervalo de 30 dias após a aplicação de gesso mineral foi suficiente para elevar os teores de $\mathrm{Ca}$ em profundidade mesmo sendo o gesso aplicado a lanço e sem incorporação, em Latossolo Amarelo distrocoeso típico com teor de argila variando de 486 a $686 \mathrm{~g} \mathrm{~kg}^{-1}$ até $0,6 \mathrm{~m}$ de profundidade considerando-se que durante o ensaio a precipitação pluviométrica acumulada foi de $2.883 \mathrm{~mm}$.

$\mathrm{O}$ teor de Ca no solo nas camadas 0,0 a $0,2 \mathrm{~m}$ e 0,2 a $0,4 \mathrm{~m}$ de profundidade não variou com o cultivo das variedades de capim elefante (Tabela 2) evidenciando que a absorção de $\mathrm{Ca}$ realizada pelo Cameroon, Gramafante e Roxo foi semelhante, como foi observado nos valores de extração de Ca por essas variedades, aos 7 meses de cultivo por Santos et al. (2012).

A aplicação de gesso mineral e o cultivo das variedades de capim elefante não provocaram redução do teor de $\mathrm{Mg}$ na camada superficial (Tabela 2); já para a camada subsuperficial, constatou-se que o teor de $\mathrm{Mg}$ variou com o uso do gesso mineral e esta variação foi dependente da variedade de capim elefante cultivada e vice-versa (Tabela 2). Quando se aplicou gesso, o teor de $\mathrm{Mg}$ aumentou significativamente com o cultivo de capim Cameroon mas não se alterou com o cultivo dos capins Gramafante e Roxo. 
Tabela 2. Teor de cálcio, magnésio e potássio em solo com e sem a aplicação de gesso e cultivados com três variedades de capim elefante



Ausência de letras indica não significância e letras diferentes indica significância pelo teste de Tukey a nível de 0,05 . Letras maiúsculas para linha e letras minúsculas para coluna

$\mathrm{Na}$ ausência de gesso os dados do teor de Mg se inverteram, ou seja, o cultivo do capim Cameroon passou a ser responsável pelos menores teores de Mg quando comparados ao Gramafante e Roxo. Provavelmente a descida do $\mathrm{Ca}$ com a aplicação do gesso mineral tenha inibido a absorção de $\mathrm{Mg}$ pelo capim Cameroon, não interferiu na absorção de $\mathrm{Mg}$ do Gramafante e facilitou a absorção desse nutriente no capim Roxo.

A maior absorção de Mg quando foi aplicado gesso, pode ser fruto do mesmo evento observado por Caíres et al. (2004) porém com o $\mathrm{K}$, e pela preferência por $\mathrm{Ca}$ apresentada pelas variedades. Segundo esses autores, é possível que este efeito esteja relacionado à liberação de $\mathrm{K}$ dos sítios de troca para a solução do solo dependendo do aumento nos teores de $\mathrm{Ca}$ trocável. Os autores constataram maior absorção de $\mathrm{K}$ pela cevada e pelo milho.

$\mathrm{O}$ teor de $\mathrm{K}$ no solo nas camadas superficial e subsuperficial não sofreu variação com a aplicação do gesso mineral (Tabela
2). Esses resultados corroboram com os encontrados por Caíres et al. (2004) que, ao analisar as alterações químicas de um Latossolo Vermelho distrófico textura argilosa e resposta do milho à calagem e aplicação de gesso, observaram que os teores de $\mathrm{K}$ trocável no solo não foram influenciados significativamente pela aplicação das doses de gesso. Zambrosi et al. (2007) também não constataram, avaliando doses de gesso em Latossolo Vermelho distrófico sob o sistema de rotação de culturas, lixiviação de K.

Em superfície e subsuperfície o cultivo das variedades de capim elefante não interferiu no teor de $\mathrm{K}$ do solo (Tabela 2) evidenciando uma capacidade semelhante de absorção sem diferenciação na extração.

A relação entre os teores de $\mathrm{Ca} / \mathrm{Mg}$ na camada superficial não foi influenciada pela aplicação do gesso mineral nem pelo cultivo das variedades de capim elefante (Tabela 3 ).

Os valores da relação entre os teores de $\mathrm{Ca} / \mathrm{Mg}$ variaram em função da aplicação de gesso mineral na camada subsuperficial,

Tabela 3. Relações cálcio/magnésio, cálcio/potássio e teor de enxofre na forma de sulfato em solo com e sem a aplicação de gesso e cultivado com três variedades de capim elefante

\begin{tabular}{|c|c|c|c|c|c|c|c|c|c|c|}
\hline \multirow{2}{*}{\multicolumn{2}{|c|}{ Fator }} & \multicolumn{2}{|c|}{$\mathrm{Ca} / \mathrm{Mg}$} & \multirow{2}{*}{ Média } & \multicolumn{2}{|c|}{$\mathrm{Ca} / \mathrm{K}$} & \multirow{2}{*}{ Média } & \multicolumn{2}{|c|}{ 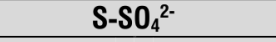 } & \multirow{2}{*}{ Média } \\
\hline & & C/gesso & S/gesso & & C/gesso & S/gesso & & C/gesso & S/gesso & \\
\hline & & \multicolumn{9}{|c|}{ Profundidade $0-0,20 \mathrm{~m}$} \\
\hline Cameroon & & 1,42 & 1,79 & 1,60 & 4,49 & 6,81 & 5,65 & 12,96 & 8,29 & $10,62 \mathrm{~b}$ \\
\hline Gramafante & & 1,59 & 3,32 & 2,46 & 4,79 & 7,75 & 6,27 & 17,88 & 12,97 & $15,42 \mathrm{a}$ \\
\hline Roxo & & 2,40 & 2,09 & 2,25 & 7,23 & 6,30 & 6,76 & 8,49 & 10,11 & $9,31 b$ \\
\hline C.V. (\%) & Subparcela & & 13,40 & & & 15,42 & & & 14,43 & \\
\hline & & \multicolumn{9}{|c|}{ Profundidade $0,20-0,40 \mathrm{~m}$} \\
\hline \multicolumn{11}{|c|}{ 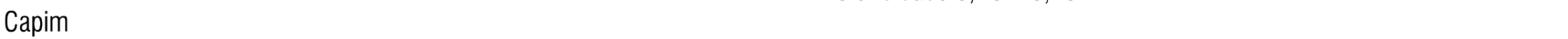 } \\
\hline \multirow{2}{*}{\multicolumn{2}{|c|}{$\begin{array}{l}\text { Cameroon } \\
\text { Gramafante }\end{array}$}} & $1,28 \mathrm{Bc}$ & $3,25 \mathrm{Aa}$ & 2,27 & 4,15 & 5,26 & 4,71 & 11,80 & 11,55 & $11,68 b$ \\
\hline & & $1,75 \mathrm{Ab}$ & $1,78 \mathrm{AC}$ & 1,77 & 2,87 & 3,17 & 3,02 & 18,26 & 16,03 & $17,15 \mathrm{a}$ \\
\hline \multicolumn{2}{|l|}{ Roxo } & $3,00 \mathrm{Aa}$ & $1,87 \mathrm{Bb}$ & 2,44 & 4,36 & 4,49 & 4,42 & 14,64 & 12,72 & $13,68 \mathrm{~b}$ \\
\hline
\end{tabular}


aplicação esta influenciada pelo cultivo das variedades de capim elefante e vice-versa (Tabela 3). Tal interação entre esses fatores nos valores da relação $\mathrm{Ca} / \mathrm{Mg}$ é decorrente da redução ou do acúmulo do teor de Mg nessa camada (Tabela 2). Como o Ca proveniente do gesso mineral parece inibir a absorção de $\mathrm{Mg}$ pelo capim Cameroon, este elemento se acumula no solo e é responsável pelo estreitamento da relação $\mathrm{Ca} / \mathrm{Mg}$. Ambiguamente, o $\mathrm{Ca}$ oriundo do gesso parece favorecer a absorção de $\mathrm{Mg}$ no capim Roxo ampliando a relação $\mathrm{Ca} / \mathrm{Mg}$. Na ausência de gesso o comportamento se inverte com o cultivo do Cameroon ampliando a relação $\mathrm{Ca} / \mathrm{Mg}$ e o Roxo estreitando-a. $\mathrm{O}$ cultivo do capim Gramafante não altera a relação $\mathrm{Ca} / \mathrm{Mg}$ na presença ou ausência de gesso mineral.

Existem divergências entre autores sobre qual é a relação $\mathrm{Ca} / \mathrm{Mg}$ ideal para gramíneas. Oliveira (1993) relata, estudando o rendimento da produção de matéria seca e nutrição do milho em função da relação $\mathrm{Ca} / \mathrm{Mg}$ no solo, que variações de 1 a 12:1 na referida relação não afetaram o rendimento de matéria seca revelando apenas uma tendência de aumento na produção de matéria seca com o aumento da relação $\mathrm{Ca} / \mathrm{Mg}$ no solo. Por outro lado, Medeiros et al. (2008) observaram, ao avaliar a produção de matéria seca da cultura do milho que, à medida em que se elevou a relação $\mathrm{Ca} / \mathrm{Mg}$ do corretivo aplicado ao solo, a produção de matéria seca reduziu drasticamente. As maiores produções foram observadas nos valores de relação $\mathrm{Ca} / \mathrm{Mg}$ até $4: 1$.

Nas camadas superficial e subsuperficial não se observou alteração no valor da relação dos teores no solo de $\mathrm{Ca} / \mathrm{K}$ nem quando se aplicou gesso mineral nem quando variedades de capim elefante foram cultivadas (Tabela 3 ).

$\mathrm{O}$ teor de $\mathrm{S}_{-} \mathrm{SO}_{4}{ }^{2-}$ no solo não se alterou com a aplicação de gesso mineral nem mesmo na camada subsuperficial (Tabela 3). Como esse ânion é responsável pelo arraste de cátions para camadas mais profundas do perfil do solo, principalmente $\mathrm{Ca}$, previa-se que ele não se acumularia na camada superficial com a aplicação de gesso, como de fato ocorreu; se esperava, no entanto, que tivesse ocorrido acúmulo de $\mathrm{S}_{-} \mathrm{SO}_{4}^{2-}$ na camada subsuperficial mas os dados não detectaram isso. Como logo após a aplicação do gesso no sulco de plantio do capim elefante ocorreu no campo experimental precipitação pluviométrica elevada (Figura 1) é provável que isto tenha favorecido o arraste de $\mathrm{S}_{-} \mathrm{SO}_{4}{ }^{2-}$ para camadas mais profundas, além de $0,4 \mathrm{~m}$ de profundidade; a análise dos dados dos teores de Ca no solo (Tabela 2) também mostra este comportamento corroborando com esta hipótese.

Constatou-se um crescimento no teor de $\mathrm{S}_{-} \mathrm{SO}_{4}{ }^{2-}$ tanto em superfície como em subsuperfície (Tabela 3) em relação ao teor de $\mathrm{S}_{-} \mathrm{SO}_{4}{ }_{4}^{2-}$ encontrado inicialmente no solo, quando de sua caracterização química (Tabela 1). Referido aumento no teor de $\mathrm{S} \mathrm{SO}_{4}{ }^{2-}$ ocorreu independente da aplicação de gesso e se deveu, possivelmente, aos $300 \mathrm{~kg} \mathrm{ha}^{-1}$ de sulfato de amônio utilizados como fonte de $\mathrm{N}$ na adubação nitrogenada.

Tanto em superfície como em subsuperfície, o cultivo de capim elefante influenciou os teores de $\mathrm{S}_{-} \mathrm{SO}_{4}{ }_{4}^{2-}$ do solo (Tabela 3). $\mathrm{O}$ teor de $\mathrm{S}_{-} \mathrm{SO}_{4}^{2-}$ foi maior quando se cultivou capim Gramafante em relação ao Cameroon e Roxo, independente da profundidade da camada estudada o que sinaliza que, possivelmente, algumas variedades apresentam preferências de absorção por $\mathrm{S}_{-} \mathrm{SO}_{4}^{2-}$.

$\mathrm{Na}$ camada superficial a aplicação de gesso mineral não influenciou o pH do solo (Tabela 4). Este resultado corrobora com o encontrado por Soratto \& Crusciol (2008) ao avaliarem atributos químicos do solo decorrentes da aplicação de calcário e gesso em sistema plantio direto.

O cultivo das variedades de capim elefante não influenciou o pH do solo na camada superficial (Tabela 4). $\mathrm{Na}$ absorção de $\mathrm{Ca}$ em que se adicionou o solo proveniente do calcário, há liberação de $\mathrm{H}^{+}$que é recepcionado pelos ânions acompanhantes $\left(\mathrm{OH}^{-} \mathrm{e}\right.$ $\mathrm{HCO}^{3-}$ ) fazendo com que o $\mathrm{pH}$ se eleve. Como em nenhuma das variedades a absorção de $\mathrm{Ca}$ foi diferenciada (Tabela 2) não houve excesso nem retração de liberação de $\mathrm{H}^{+}$que pudesse influenciar na diminuição ou elevação do $\mathrm{pH}$.

$\mathrm{Na}$ camada subsuperficial a aplicação de gesso mineral diminuiu o pH do solo (Tabela 4). Evidencia-se, então, uma

Tabela 4. Acidez ativa, alumínio trocável e saturação por alumínio no complexo de troca em solo com e sem a aplicação de gesso e cultivado com três variedades de capim elefante

\begin{tabular}{|c|c|c|c|c|c|c|c|c|c|c|}
\hline \multirow{3}{*}{\multicolumn{2}{|c|}{ Fator }} & \multicolumn{2}{|c|}{$\mathrm{pH}$} & \multirow{3}{*}{ Média } & \multicolumn{2}{|c|}{ Al } & \multirow{2}{*}{ Média } & \multicolumn{2}{|c|}{$\mathbf{m}$} & \multirow{2}{*}{ Média } \\
\hline & & \multirow{2}{*}{ C/gesso } & \multirow{2}{*}{ S/gesso } & & C/gesso & S/gesso & & C/gesso & S/gesso & \\
\hline & & & & & \multicolumn{3}{|c|}{$\left(\mathrm{cmol}_{\mathrm{c}} \mathrm{dm}^{-3}\right)$} & \multicolumn{3}{|c|}{$(\%)$} \\
\hline & & \multicolumn{9}{|c|}{ Profundidade $0-0,20 \mathrm{~m}$} \\
\hline \multicolumn{2}{|l|}{ Cameroon } & 5,28 & 5,50 & 5,39 & 0,21 & 0,26 & $0,24 \mathrm{~b}$ & 7,64 & 10,95 & $9,30 \mathrm{~b}$ \\
\hline \multicolumn{2}{|l|}{ Gramafante } & 5,20 & 5,18 & 5,19 & 0,44 & 0,34 & $0,39 \mathrm{a}$ & 18,02 & 13,68 & $15,85 \mathrm{a}$ \\
\hline \multicolumn{2}{|l|}{ Roxo } & 5,18 & 4,93 & 5,05 & 0,40 & 0,44 & $0,42 \mathrm{a}$ & 15,58 & 16,49 & $16,03 \mathrm{a}$ \\
\hline CV (\%) & Subparcela & \multirow{2}{*}{\multicolumn{8}{|c|}{$\begin{array}{c}14,04 \\
\text { Profundidade } 0,20-0,40 \mathrm{~m}\end{array}$}} & \\
\hline & & & & & & & & & & \\
\hline \multicolumn{11}{|c|}{ 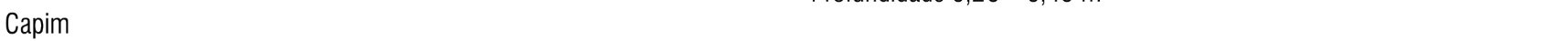 } \\
\hline \multirow{2}{*}{\multicolumn{2}{|c|}{$\begin{array}{l}\text { Cameroon } \\
\text { Gramafante }\end{array}$}} & 4,53 & 5,03 & $4,78 \mathrm{a}$ & 0,75 & 0,75 & 0,75 & 40,61 & 41,64 & 41,12 \\
\hline & & 4,48 & 4,73 & $4,60 \mathrm{~b}$ & 0,83 & 0,80 & 0,82 & 49,60 & 45,76 & 47,68 \\
\hline Roxo & & 4,25 & 4,73 & $4,49 \mathrm{~b}$ & 0,86 & 0,79 & 0,83 & 46,16 & 44,71 & 45,43 \\
\hline
\end{tabular}

Ausência de letras indica não significância e letras diferentes indicam significância pelo teste de Tukey a nível de 0,05 . Letras maiúsculas para linha e letras minúsculas para coluna 
provável atuação do gesso nessa camada mesmo não se tendo comprovado acúmulo de $\mathrm{Ca}$ (Tabela 2) nem de $\mathrm{S}_{-} \mathrm{SO}_{4}^{2-}$ (Tabela 3 ).

Quando o $\mathrm{Ca}^{2+}$ desloca o $\mathrm{Al}^{3+}$ do complexo de troca fazendo com que o $\mathrm{Al}^{3+}$ permaneça em solução, se não houver $\mathrm{SO}_{4}^{2-}$ suficiente para a formação de $\mathrm{Al}(\mathrm{SO} 4)^{+}$, o excesso de $\mathrm{Al}^{3+}$ em solução poderá hidrolisar-se e protonar, formando os íons $\mathrm{Al}(\mathrm{OH})^{2+}$ e $\mathrm{Al}(\mathrm{OH})^{2+}$, liberando $\mathrm{H}^{+}$em solução que não pode ser recepcionado pelo $\mathrm{SO}_{4}{ }^{2-}$, diminuindo o $\mathrm{pH}$ do solo (Alvarez V. et al., 1999).

Esta redução do pH na camada subsuperficial pela aplicação de gesso contraria os resultados encontrados por Caíres et al. (2004; 2006) mas foi observada por Ernani et al. (2001) ao avaliarem modificações químicas em solos ácidos ocasionadas pela aplicação do insumo em colunas de lixiviação e também atribuíram este efeito à hidrólise do Al.

$\mathrm{O}$ pH do solo na camada subsuperficial foi alterado pelo cultivo das variedades de capim elefante (Tabela 4). A absorção de cátions básicos como $\mathrm{Ca}, \mathrm{Mg}$ e $\mathrm{K}$ provoca extrusão de $\mathrm{H}^{+}$. Se o pH do solo nesta camada foi alterado pelo cultivo dessas plantas é porque houve uma absorção considerável de cátions que não se limitou à camada superficial. É possível que o sistema radicular dessas variedades de capim elefante tenha se expandido com o uso do gesso favorecendo a absorção de cátions em subsuperfície. Os capins Gramafante e Roxo provocaram mais reduções no $\mathrm{pH}$ do solo que o capim Cameroon (Tabela 4) devido, possivelmente, a uma expansão maior e eficiência de seus sistemas radiculares, tornando-os mais capazes de absorver em profundidade.

A aplicação de gesso mineral não reduziu o teor de $\mathrm{Al}$ do solo nem em superfície nem, tampouco, em subsuperfície (Tabela 4). A redução do teor de Al em camadas mais profundas do perfil do solo é um dos principais objetivos do uso do gesso, cujo comportamento não foi observado neste trabalho, provavelmente pela lixiviação do Ca para além dos $0,4 \mathrm{~m}$ de profundidade, pela intensidade da precipitação pluviométrica que ocorreu após a aplicação do gesso mineral.

Com a aplicação de gesso ocorre a formação de diversos complexos envolvendo o ânion $\mathrm{SO}_{4}{ }^{2-}$, dentre eles $\mathrm{Al}\left(\mathrm{SO}_{4}\right)^{+}$que teoricamente é Al não-trocável (Zambrosi et al., 2007). Por ainda apresentar carga supõe-se que este complexo pode ficar adsorvido na micela do solo (mineral ou orgânica), e por ter apenas uma carga a atração eletrostática pela micela é pequena. Levanta-se, então, a hipótese de que o extrator utilizado para a determinação de $\mathrm{Al}$ trocável, que é uma solução de $\mathrm{KCl} 1$ mol L-1, pode ter removido o complexo $\mathrm{Al}\left(\mathrm{SO}_{4}\right)^{+}$da micela do solo para o extrato e a titulação com $\mathrm{NaOH}$ ter incluído referido complexo como Al trocável, não permitindo que se avalie a atuação do gesso pela redução dos teores trocáveis de Al. No entanto, a formação do complexo $\mathrm{Al}\left(\mathrm{SO}_{4}\right)^{+}$é uma das consequências da atuação do gesso visto que, nesta forma, o Al não é tóxico e em regiões de elevada precipitação pode ser facilmente lixiviado para fora do alcance das raízes das plantas (Alvarez V. et al., 1999).

Rocha et al. (2008) também não encontraram alterações significativas nos teores de Al em superfície e subsuperfície pela aplicação de gesso mineral em solo cultivado com canade-açúcar, aos 30 e 480 dias após a aplicação, corroborando com os resultados deste trabalho.
A saturação por Al também não foi influenciada pela aplicação de gesso mineral em nenhuma das camadas de solo estudadas (Tabela 4). Na gessagem espera-se que o Ca migre para camadas mais profundas do perfil do solo e reduza a saturação por $\mathrm{Al}$, ou seja, diminua sua participação na capacidade de troca de cátions efetiva do solo em profundidade. Especificamente neste trabalho, como se tem constatado que a elevada precipitação pluviométrica foi responsável por um arraste de Ca para além dos $0,4 \mathrm{~m}$ de profundidade, o gesso provavelmente não atuou de forma efetiva nesta camada de solo.

Resultados contrários a esses no teor e na saturação por $\mathrm{Al}$ foram encontrados por Silva et al. (1997) ao relatarem que a maior redução no teor de $\mathrm{Al}^{3+}$ pela aplicação de gesso foi de $0,05 \mathrm{cmol}_{\mathrm{c}}$ $\mathrm{kg}^{-1}$, na maior dose utilizada que correspondeu a $6 \mathrm{Mg} \mathrm{ha}^{-1}$, nas profundidades de $0,0-0,2 ; 0,2-0,4$ e $0,4-0,6$ m porém observaram reduções de até $47,96 \%$ na saturação por $\mathrm{Al}^{3+}$ com a aplicação da maior dose do insumo, na profundidade de 0,2-0,4 m.

$\mathrm{O}$ cultivo das variedades de capim elefante influenciou o teor e a saturação por Al na camada superficial do solo (Tabela 4) especificamente pelo comportamento do cultivo do capim Cameroon, que reduziu o teor e a saturação por $\mathrm{Al}$ do solo em superfície. A análise dos dados de $\mathrm{pH}$ demonstra que na camada superficial após o cultivo do Cameroon houve tendência no aumento do $\mathrm{pH}$, que se confirma estatisticamente na camada subsuperficial (Tabela 4) sugerindo que esta variedade de capim elefante foi, possivelmente, extratora de $\mathrm{Al}$; desta forma, é provável que o $\mathrm{pH}$ do solo com o cultivo de capim Cameroon não se tenha reduzido pela retirada de Al que esta planta realizou, o que pode credenciá-la como variedade tolerante à acidez trocável do solo, sugerindo-se que mais estudos sejam realizados com tal genótipo em solos ácidos e ricos em Al.

A aplicação de gesso promoveu aumento na produção de matéria fresca apenas da variedade Cameroon (Figura 2A), com ganho relativo de $23 \mathrm{Mg} \mathrm{ha}^{-1}$. Na presença de gesso as produções de matéria fresca das variedades Cameroon, Gramafante e Roxo se mostraram diferentes (Figura 2A) porém na ausência do insumo as variedades Cameroon e Gramafante apresentaram produções semelhantes de matéria fresca, maiores à apresentada pela variedade Roxo. Custódio et al. (2005) encontraram, estudando o efeito do gesso na produção de capim-tanzânia, efeito positivo na produção de matéria fresca com o aumento da dose, corroborando com os resultados deste trabalho.

A aplicação do gesso proporcionou aumento de $9 \mathrm{Mg} \mathrm{ha}^{-1}$ $(37,5 \%)$ na produção de matéria seca na variedade Cameroon mas não provocou alterações significativas na produção das variedades Gramafante e Roxo (Figura 2B). Na presença do gesso as variedades Cameroon e Gramafante apresentaram produções de matéria seca diferentes da variedade Roxo; a maior produção foi observada pela variedade Cameroon com $33 \mathrm{Mg} \mathrm{ha}^{-1}$. Na ausência do insumo a produção de matéria seca das variedades Cameroon e Gramafante foi semelhante (Figura 2B). Desta forma, a variedade de capim elefante Cameroon teve sua produção de matéria seca potencializada pelo gesso.

Custódio et al. (2005) relatam elevação de $37 \%$ na produção de matéria seca com adição de gesso em capim-tanzânia quando aplicaram $0,5 \mathrm{Mg} \mathrm{ha}^{-1}$, dose próxima à utilizada neste trabalho; na dose de 2,93 $\mathrm{Mg} \mathrm{ha}^{-1}$ os autores constataram o maior aumento de produtividade, $120 \%$ na produção de matéria seca. 


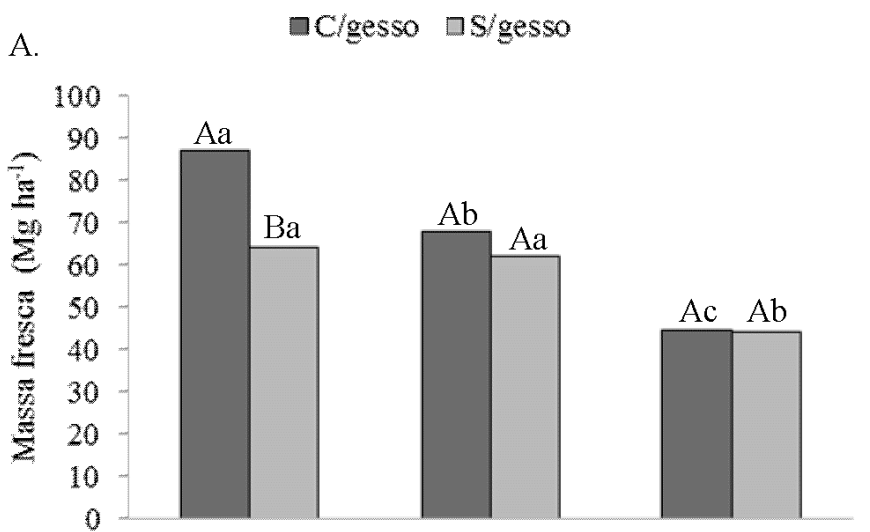

B.

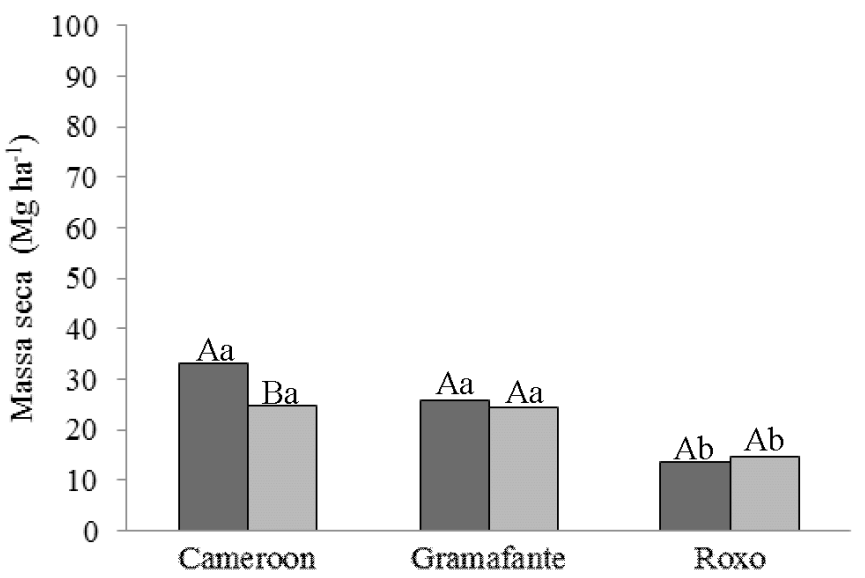

Letras maiúsculas comparam a presença e ausência de gesso dentro de cada variedade e letras minúsculas comparam as variedades na presença e ausência de gesso. Letras iguais não diferem (Tukey, $p \leq 0,05$ )

Figura 2. Produção de matéria fresca (A) e seca (B) de três variedades de capim elefante na presença e ausência de gesso

\section{CONCLUSÕES}

1. As doses aplicadas de gesso mineral não alteraram os teores de $\mathrm{Ca}, \mathrm{S}_{-} \mathrm{SO}_{4}{ }^{2-}, \mathrm{Al}$ e de sua saturação.

2. Não foram observadas alterações nos teores de $\mathrm{Mg}$ e $\mathrm{K}$ em subsuperfície, porém houve redução do $\mathrm{pH}$ do solo com a aplicação do insumo.

3. O cultivo de capim Cameroon elevou o $\mathrm{pH}$ do solo em subsuperfície e reduziu o teor e a saturação por $\mathrm{Al}$ em superfície.

4. A variedade de capim elefante Cameroon apresentou resposta à aplicação de gesso.

\section{Agradecimentos}

Ao Programa de Pós-Graduação em Ciência do Solo da UFRPE; à FACEPE, ao CNPq e ao IPA, pelo apoio no financiamento e realização da pesquisa.

\section{Literatura Citada}

Abichequer, A. D.; Bohnen, H.; Anghinoni, I. Absorção, translocação e utilização de fósforo por variedades de trigo submetidas à toxidez de alumínio. Revista Brasileira de Ciência do Solo, v.27, p.373-378, 2003.
Alvarez V., V. H.; Dias, L. E.; Ribeiro, A. C.; Souza, R. B. Uso de gesso agrícola. In: Ribeiro, A. C.; Guimarães, P. T. G.; Alvarez V., V. H. Recomendações para o uso de corretivos e fertilizantes em Minas Gerais, $5^{\mathrm{a}}$ aproximação. Viçosa: UFV, 1999. Cap.10, p.67-78.

Alvarez V.; V. H. Dias, L. E.; Ribeiro Junior, E. S.; Souza, R. B. de; Fonseca, C. A. Métodos de análises de enxofre em solos e plantas. 1.ed.Viçosa: UFV, 2001. 131p.

Caíres, E. F.; Churka, S.; Garbuio, F. J.; Ferrari, R. A.; Morgano, M. A. Soybean yield and quality as a function of lime and gypsum applications. Scientia Agricola, v.63, p.370-379, 2006.

Caíres, E. F.; Kusman, M. T.; Barth, G.; Garbuio, F. J.; Padilha, J. M. Alterações químicas do solo e resposta do milho à calagem e aplicação de gesso. Revista Brasileira de Ciência do Solo, v.28, p.125-136, 2004.

Cavalcanti, A. C.; Lopes, O. F. Condições edafoclimáticas da Chapada do Araripe e viabilidade de produção sustentável de culturas. Brasília: EMBRAPA, Centro de Pesquisa Agropecuária do Trópico Semiárido, Unidade de Execução de Pesquisa e Desenvolvimento, 1994. 41p.

CPRM - Companhia de Pesquisa de Recursos Minerais. Serviço Geológico do Brasil Projeto. Cadastro de fontes de abastecimento por água subterrânea. Diagnóstico do município de Araripina, estado de Pernambuco. Recife: CPRM/PRODEEM, 2005. 26p.

Custódio, D. P.; Oliveira, I. P. D.; Costa, K. A. D. P.; Santos, R. S. M.; Faria, C. D. Avaliação do gesso no desenvolvimento e produção do capim-tanzânia. Ciência Animal Brasileira, v.6, p.27-34, 2005.

EMBRAPA - Empresa Brasileira de Pesquisa Agropecuária. Manual de métodos de análises de solos. 2.ed. Rio de Janeiro: Centro Nacional de Pesquisa de Solos, 1997. 212p.

EMBRAPA - Empresa Brasileira de Pesquisa Agropecuária. Manual de análises químicas de solos, plantas e fertilizantes. 2.ed. Brasília: Embrapa Informação Tecnológica; Rio de Janeiro: Embrapa Solos, 2009. 627p.

Ernani, P. R.; Ribeiro, M. S.; Bayer, C. Modificações químicas em solos ácidos ocasionadas pelo método de aplicação de corretivos da acidez e de gesso agrícola. Scientia Agricola, v.58, p.825-831, 2001.

IPA - Instituto Agronômico de Pernambuco. Recomendações de adubação para o Estado de Pernambuco: $2^{\mathrm{a}}$ aproximação. 3.ed. Recife: Instituto Agronômico de Pernambuco, 2008. 212p.

Medeiros, J. C.; Albuquerque, J. A.; Mafra, A. L.; Rosa, J. D.; Gatiboni, L. C. Relação cálcio:magnésio do corretivo da acidez do solo na nutrição e no desenvolvimento inicial de plantas de milho em um Cambissolo Húmico Álico. Semina: Ciências Agrárias, v.29, p.799-806, 2008.

Millán, G.; Vázquez, M.; Terminiello, A.; Sbuscio, D. S. Efecto de las enmiendas básicas sobre el complejo de cambio en algunos suelos ácidos de la región pampeana. Ciencia del Suelo, v.28, p.131-140, 2010.

Morais, R. F. D.; Souza, B. J. D.; Leite, J. M.; Soares, L. H. de B.; Alves, B. J. R.; Boddey, R. M.; Urquiaga, S. Elephant grass genotypes for bioenergy production by direct biomass combustion. Pesquisa Agropecuária Brasileira, v.44, p.133140, 2009.

Oliveira, E. L. de. Rendimento de matéria seca e absorção de cálcio e magnésio pelo milho em função da relação cálcio/ magnésio do solo. Revista Brasileira de Ciência do Solo, v.17, p.383-388, 1993. 
Rheinheimer, D. S.; Petry, C.; Kaminski, J.; Bartz, H. R. Influência do estresse de alumínio em plantas de fumo virgínia: I. Efeito no sistema radicular, na absorção de fósforo e cálcio e na produtividade de matéria seca. Revista Brasileira de Ciência do Solo, v.18, p.63-68, 1994.

Rocha, A. T.; Oliveira, A. T.; Rodrigues, A. N.; Lira Júnior, M. A.; Freire, F. J. Emprego do gesso do Araripe na melhoria do ambiente radicular da cana-de-açúcar. Revista Brasileira de Ciências Agrárias, v.3, p.307-312, 2008.

Ruiz, H. A. Incremento da exatidão da análise granulométrica do solo por meio da coleta da suspensão (silte + argila). Revista Brasileira de Ciência do Solo, v.29, p.297-300, 2005.

Saldanha, E. C. M.; Rocha, A. T.; Oliveira, E. C. A.; Nascimento, C. W. A.; Freire, F. J. Uso do gesso mineral em Latossolo cultivado com cana-de-açúcar. Revista Caatinga, v.20, p.36-42, 2007.
Santos, R. L.; Azevedo, V. M. de; Freire, F. J.; Rocha, A. T. da; Tavares, J. A.; Freire, M. B. G. dos S. Extração e eficiência de uso de nutrientes em capim-elefante na presença de gesso. Revista Brasileira de Ciência do Solo, v.36, p.497-505, 2012.

Silva, N. M.; Raij, B. van; Carvalho, L. H.; Bataglia, O. C.; Kondo, J. I. Efeitos do calcário e do gesso nas características químicas do solo e na cultura do algodão. Bragantia, v.56, p.389-401, 1997.

Soratto, R. P.; Crusciol, C. A. C. Atributos químicos do solo decorrentes da aplicação em superfície de calcário e gesso em sistema plantio direto recém-implantado. Revista Brasileira de Ciência do Solo, v.32, p.675-688, 2008.

Zambrosi, F. C. B.; Alleoni, L. R. F.; Caíres, E. F. Aplicação de gesso agrícola e especiação iônica da solução de um Latossolo sob sistema plantio direto. Ciência Rural, v.37, p.110-117, 2007. 